FACTA UNIVERSITATIS

Series: Mechanical Engineering Vol. 16, N 2, 2018, pp. 171 - 191

https://doi.org/10.22190/FUME180503018P

Original research article

\title{
NORMALIZED WEIGHTED GEOMETRIC BONFERRONI MEAN OPERATOR OF INTERVAL ROUGH NUMBERS - APPLICATION IN INTERVAL ROUGH DEMATEL-COPRAS MODEL
}

\author{
UDC 519.8:656
}

\section{Dragan Pamučar, Darko Božanić, Vesko Lukovac, Nenad Komazec}

\author{
University of Defence in Belgrade, Military Academy, Serbia
}

\begin{abstract}
This paper presents a new approach to the treatment of uncertainty and imprecision in the multi-criteria decision-making based on interval rough numbers (IRN). The IRN-based approach provides decision-making using only internal knowledge for the data and operational information of the decision-maker. A new normalized weighted geometric Bonferroni mean operator is developed on the basis of the IRN for the aggregation of the IRN (IRNWGBM). Testing of the IRNWGBM operator is performed through the application in a hybrid IR-DEMATEL-COPRAS multi-criteria model which is tested on the real case of selecting an optimal direction for the creation of a temporary military route. The first part of the hybrid model is the IRN DEMATEL model, which provides objective expert evaluation of criteria under the conditions of uncertainty and imprecision. In the second part of the model, the evaluation is carried out by using the new interval rough COPRAS technique.
\end{abstract}

Key Words: Interval Rough Numbers, DEMATEL, COPRAS, Bonferroni Mean Operator

\section{INTRODUCTION}

The decision-making theory comprises many multi-criteria decision-making models (MCDM) that support solving of various problems such as those in management science, urban planning issues, problems in natural sciences and military affairs, etc. According to Triantaphyllou and Mann [1], MCDM plays an important role in real-life problems, considering that there are many everyday decisions to be taken which include a number of criteria, while according to Chen et al. [2], the multi-criteria decision making is an

Received May 03, 2018 / Accepted June 07, 2018

Corresponding author: Dragan Pamučar

University of Defence in Belgrade, Military Academy, Pavla Jurišica Šturma 33, 11000 Belgrade, Serbia

E-mail: dpamucar@gmail.com 
efficient systematic and quantitative manner of solving vital real-life problems in the presence of a large number of alternatives and several (opposing) criteria.

The MCDM area is an area that has experienced remarkable advances in the last two decades, as demonstrated by numerous models developed in this area: the AHP (Analytical Hierarchical Process) method [3, 4], the TOPSIS (Technique for Order of Preference by Similarity to the Ideal Solution method) method [5], the VIKOR (VlseKriterijumska Optimizacija I Kompromisno Resenje) method [6], the DEMATEL (Decision Making Trial and Evaluation Laboratory) method [7], the ELECTRE (ELimination and Choice Expressing REALITY) method [8], the COPRAS (Complex Proportional Assessment) method [9], the MABAC (Multi-Attributive Border Approximation area Comparison) [10, 11], the EDAS (Evaluation Based on Distance from Average Solution) method [12,13], the CODAS (COmbinative Distance-based Assessment) method [14, 15], MAIRCA (MultiAttributive Ideal-Real Comparative Analysis) method [16,17].

As already mentioned, the MCDM models are used to solve many problems. In complex MCDM models, a large number of experts participate in order to find the most objective solution [18]. Such models require the application of mathematical aggregators to obtain an aggregated initial decision-making matrix. There are many traditional aggregators used in group MCDM models, such as Dombi aggregators [19], Bonferroni aggregators [20], Einstein and Hamacher operators [21], Heronian aggregation operators [22]. These aggregation operators have been widely used in theories of uncertainty such as fuzzy MCDM models [23-26], single-valued neutrosophic MCDM models [27-29], linguistic neutrosophic models [30, 31], etc.

In this paper, a new approach in the theory of rough sets is applied to the treatment of uncertainty and imprecision contained in the data in group decision-making, namely, an approach based on interval rough numbers (IRN). Since this is a new approach, only traditional arithmetic aggregators have been used so far in the MCDM models based on rough numbers [34-36]. This paper presents the application and development of a new normalized weighted geometric Bonferroni mean operator for the IRN aggregation (IRNWGBM). The application of the new IRNWGBM operator is shown in hybrid IRDEMATEL-COPRAS model. In the literature, there are numerous examples of using the DEMATEL model for determining weight coefficients [17, 37], as well as the COPRAS model for evaluating alternatives [9]. However, so far in the literature the DEMATEL and COPRAS models based on interval rough numbers are not familiar. To the best of this author's knowledge, there is no hybrid IR-DEMATEL-COPRAS model in the field of MCDM, which in this way takes into consideration mutual dependence of criteria, evaluates alternatives and treats imprecision and uncertainty with the IRN. One of the goals of this paper is the development of a new IRNWGBM operator for the IRN aggregation. The second goal of this paper is the improvement of the MCDM area through the development of a new hybrid IR-DEMATEL-COPRAS model based on the IRN.

The rest of the paper is organized as follows. The second chapter presents a mathematical analysis of interval rough numbers and the development of new IRNWGBM operator. The third chapter presents the algorithm of hybrid IR-DEMATEL-COPRAS model, which is later tested in the fourth chapter using a real example of selecting an optimal direction for the creation of a temporary military route. In the fifth chapter, the concluding observations are presented with a special emphasis on the directions for future research. 


\section{INTERVAL ROUGH NUMBERS AND NORMALIZED WEIGHTED GEOMETRIC BONFERRONI \\ MEAN OPERATOR}

If we suppose that there is a set of $k$ classes which present the preferences of a DM, $R=\left(J_{1}, J_{2}, \ldots, J_{k}\right)$, provided that these belong to the series which meets the condition where $J_{1}<J_{2}<, \ldots,<J_{k}$ and another set of $m$ classes which also present the preferences of a DM, $R^{*}=\left(I_{1}, I_{2}, \ldots, I_{k}\right)$. All the objects are defined in the universe and related to the preferences of a DM. In $R^{*}$ every object class is presented in the interval $I_{i}=\left\{I_{l i} I_{u i}\right\}$, meeting the condition where $I_{l i} \leq I_{u i}(1 \leq i \leq m)$, as well as the condition where $I_{l i}, I_{u i} \in R$. Then, $I_{l i}$ presents the lower limit of the interval, while $I_{u i}$ presents the upper limit of the interval of the $i$-th class of objects. If both upper and lower limits of the class of objects are sorted so that $I_{1 I}^{*}<I_{l 2}^{*}<\ldots<I_{l j}^{*}, I^{*}{ }_{u 1}<I_{2 u}^{*}<\ldots<I_{u k}^{*}(1 \leq j, k \leq m)$, respectively, then we can define the two new sets containing the lower class of objects $R_{l}{ }^{*}=\left(I^{*}{ }_{l 1}, I_{l 2}^{*}, \ldots, I_{l j}^{*}\right)$ and upper class of objects $R_{u}{ }^{*}=\left(I_{u 1}^{*}, I_{u 2}^{*}, \ldots, I_{u k}^{*}\right)$, respectively. Then, for any class of the objects $I_{l i}^{*} \in R$ $(1 \leq i \leq j)$ and $I_{u i}^{*} \in R \quad(1 \leq i \leq k)$ we can define the lower approximation $I^{*}{ }_{l i}$ and $I^{*}{ }_{u i}$ as follows [38]:

$$
\begin{aligned}
& \underline{\operatorname{Apr}}\left(I_{l i}^{*}\right)=\bigcup\left\{Y \in U / R_{l}^{*}(Y) \leq I_{l i}^{*}\right\} \\
& \underline{\operatorname{Apr}}\left(I_{u i}^{*}\right)=\bigcup\left\{Y \in U / R_{u}^{*}(Y) \leq I_{u i}^{*}\right\}
\end{aligned}
$$

The upper approximations $I_{l i}^{*}$ and $I_{u i}^{*}$ are defined by applying the following expressions:

$$
\begin{aligned}
& \overline{\operatorname{Apr}}\left(I_{l i}^{*}\right)=\bigcup\left\{Y \in U / R_{l}^{*}(Y) \geq I_{l i}^{*}\right\} \\
& \overline{\operatorname{Apr}}\left(I_{u i}^{*}\right)=\bigcup\left\{Y \in U / R_{u}^{*}(Y) \geq I_{u i}^{*}\right\}
\end{aligned}
$$

Both classes of objects (upper and lower class of the objects $I_{l i}^{*}$ and $I_{u i}^{*}$ ) are defined by their lower limits $\underline{\operatorname{Lim}}\left(I_{l i}^{*}\right)$ and $\underline{\operatorname{Lim}}\left(I_{u i}^{*}\right)$ and upper limits $\overline{\operatorname{Lim}}\left(I_{l i}^{*}\right)$ and $\overline{\operatorname{Lim}}\left(I_{u i}^{*}\right)$, respectively

$$
\begin{aligned}
& \underline{\operatorname{Lim}}\left(I_{l i}^{*}\right)=\frac{1}{M_{L}} \sum R_{l}^{*}(Y) \mid Y \in \underline{\operatorname{Apr}}\left(I_{l i}^{*}\right) \\
& \underline{\operatorname{Lim}}\left(I_{u i}^{*}\right)=\frac{1}{M_{L}^{*}} \sum R_{u}^{*}(Y) \mid Y \in \underline{\operatorname{Apr}}\left(I_{u i}^{*}\right)
\end{aligned}
$$

where $M_{L}$ and $M_{L}^{*}$ present the sum of objects contained in the lower approximation of the classes of objects $I_{l i}^{*}$ and $I_{u i}^{*}$, respectively. The upper limits $\overline{\operatorname{Lim}}\left(I_{l i}^{*}\right)$ and $\overline{\operatorname{Lim}}\left(I_{u i}^{*}\right)$ are defined by Eqs. (7) and (8)

$$
\begin{aligned}
& \overline{\operatorname{Lim}}\left(I_{l i}^{*}\right)=\frac{1}{M_{U}} \sum R_{l}^{*}(Y) \mid Y \in \overline{\operatorname{Apr}}\left(I_{l i}^{*}\right) \\
& \overline{\operatorname{Lim}}\left(I_{u i}^{*}\right)=\frac{1}{M_{U}^{*}} \sum R_{u}^{*}(Y) \mid Y \in \overline{\operatorname{Apr}}\left(I_{u i}^{*}\right)
\end{aligned}
$$


where $M_{U}$ and $M_{U}^{*}$ present the sum of objects contained in the upper approximation of the classes of objects $I^{*}{ }_{l i}$ and $I^{*}{ }_{u i}$, respectively. Then, the uncertain class of objects $I^{*}{ }_{l i}$ and $I^{*}{ }_{u i}$ can be shown with their lower and upper limit

$$
\begin{aligned}
R N\left(I_{l i}^{*}\right) & =\left[\overline{\operatorname{Lim}}\left(I_{l i}^{*}\right), \underline{\operatorname{Lim}}\left(I_{l i}^{*}\right)\right] \\
R N\left(I_{u i}^{*}\right) & =\left[\overline{\operatorname{Lim}}\left(I_{u i}^{*}\right), \underline{\operatorname{Lim}}\left(I_{u i}^{*}\right)\right]
\end{aligned}
$$

As can be seen, every class of objects is defined by its upper and lower limits, which consist of interval rough numbers, defined as follows

$$
\operatorname{IRN}\left(I_{i}^{*}\right)=\left[R N\left(I_{l i}^{*}\right), R N\left(I_{u i}^{*}\right)\right]
$$

Interval rough numbers are characterized by specific arithmetic operations differing from the arithmetic operations with classic rough numbers. Detailed arithmetic operations with the IRN and mutual comparison of the IRN are presented in Pamučar et al. [34].

Definition 1 [20]. Let $\left(a_{1}, a_{2}, \ldots, a_{n}\right)$ be a set of non-negative numbers, the function NWGBM: $R^{n} \rightarrow R, w_{i}(i=1,2, \ldots, n)$ be the relative weight of $a_{i}(i=1,2, \ldots, n), w_{i} \in[0,1]$ and $\sum_{i=1}^{n} w_{i}=1$. If $p, q \geq 0$ and normalized weighted geometric Bonferroni mean operator satisfies:

$$
N W G B M^{p, q}\left(a_{1}, a_{2}, \ldots, a_{n}\right)=\frac{1}{p+q} \prod_{i, j=1}^{n}\left(p a_{i}+q a_{j}\right)^{\frac{w_{i} w_{j}}{1-w_{i}}}
$$

Then NWGBM ${ }^{\mathrm{p}, \mathrm{q}}$ is called a normalized weighted geometric Bonferroni mean (NWGBM) operator.

Definition 2 Set $\operatorname{IRN}\left(\xi_{i}\right)=\left[R N\left(\xi_{i}^{L}\right), R N\left(\xi_{i}^{U^{\prime}}\right)\right]=\left(\left[\xi_{i}^{L}, \xi_{i}^{U}\right],\left[\xi_{i}{ }^{\prime}, \xi_{i}^{\prime}\right]\right)(i=1,2, . ., n)$ as a collection of interval rough numbers (IRNs) in $\Psi$, then the IRNWBM can be defined as follows

$$
\operatorname{IRNWGBM} M^{p, q}\left(\operatorname{IRN}\left(\xi_{1}\right), \operatorname{IRN}\left(\xi_{2}\right), \ldots, \operatorname{IRN}\left(\xi_{n}\right)\right)=\frac{1}{p+q} \prod_{\substack{i, j=1 \\ i \neq j}}^{n}\left(p \operatorname{IRN}\left(\xi_{i}\right)+q \operatorname{IRN}\left(\xi_{j}\right)\right)^{\frac{w_{i} w_{j}}{1-w_{i}}}
$$

where $w_{i}$ is the relative weight of $\operatorname{IRN}\left(\xi_{i}\right), w_{i} \in[0,1]$ and $\sum_{i=1}^{n} w_{i}=1, w_{j}$ is the relative weight of $\operatorname{IRN}\left(\xi_{j}\right), w_{j} \in[0,1]$ and $\sum_{j=1}^{n} w_{j}=1$.

According to the arithmetic operations applied in interval numbers and Definition 2, we can obtain the following theorems:

Theorem 1 Set $\operatorname{IRN}\left(\xi_{i}\right)=\left[R N\left(\xi_{i}^{L}\right), R N\left(\xi_{i}^{U}\right)\right]=\left(\left[\xi_{i}^{L}, \xi_{i}^{U}\right],\left[\xi_{i}{ }^{\prime}, \xi_{i}^{\prime} U\right)(i=1,2, . ., n)\right.$ as a collection of IRNs in $\Psi$, then according to Eq. (12), aggregation results obtained is still RN, and we can get the following aggregation formula 


$$
\begin{aligned}
& \operatorname{IRNWGBM} M^{p, q}\left(\operatorname{IRN}\left(\xi_{1}\right), \operatorname{IRN}\left(\xi_{2}\right), \ldots, \operatorname{IRN}\left(\xi_{n}\right)\right)=\frac{1}{p+q} \prod_{\substack{i, j=1 \\
i \neq j}}^{n}\left(p \operatorname{IRN}\left(\xi_{i}\right)+q \operatorname{IRN}\left(\xi_{j}\right)\right) \\
& =\left[\frac{1}{p+q} \prod_{\substack{i, j=1 \\
i \neq j}}^{n}\left(p R N\left(\xi_{i}^{L}\right)+q R N\left(\xi_{j}^{L}\right)\right)^{\frac{w_{i} w_{j}}{1-w_{i}}}, \frac{1}{p+q} \prod_{\substack{i, j=1 \\
i \neq j}}^{n}\left(p R N\left(\xi_{i}^{\prime}\right)+q \overline{\operatorname{Lim}}\left(\xi_{j}^{\prime}\right)\right)^{\frac{w_{i} w_{j}}{1-w_{i}}}\right] \\
& =\left[\begin{array}{l}
{\left[\frac{1}{p+q} \prod_{\substack{i, j=1 \\
i \neq j}}^{n}\left(p \xi_{i}^{L}+q \xi_{j}^{L}\right)^{\frac{w_{i} w_{j}}{1-w_{i}}}, \frac{1}{p+q} \prod_{\substack{i, j=1 \\
i \neq j}}^{n}\left(p \xi_{i}^{U}+q \xi_{j}^{U}\right)^{\frac{w_{i} w_{j}}{1-w_{i}}}\right],} \\
\left.\left[\frac{1}{p+q} \prod_{\substack{i, j=1 \\
i \neq j}}^{n}\left(p \xi_{i}^{\prime L}+q \xi_{j}^{L}\right)^{\frac{w_{i} w_{j}}{1-w_{i}}}, \frac{1}{p+q} \prod_{\substack{i, j=1 \\
i \neq j}}^{n}\left(p \xi_{i}^{\prime}+q \xi_{j}^{\prime}\right)^{\frac{w_{i} w_{j}}{1-w_{i}}}\right]\right)
\end{array}\right.
\end{aligned}
$$

Proof.

$$
\begin{aligned}
& \operatorname{IRN}\left(\xi_{i}\right)=\left[R N\left(\xi_{i}^{L}\right), R N\left(\xi_{i}^{U}\right)\right]=\left(\left[\xi_{i}^{L}, \xi_{i}^{U}\right],\left[\xi_{i}^{L}, \xi_{i}^{U}\right]\right) ; \\
& \operatorname{pIRN}\left(\xi_{i}\right)=\left[p R N\left(\xi_{i}^{L}\right), p R N\left(\xi_{i}^{\prime}\right)\right]=\left(\left[p \xi_{i}^{L}, p \xi_{i}^{U}\right],\left[p \xi_{i}^{L}, p \xi_{i}^{\prime}\right]\right) ; \\
& q \operatorname{IRN}\left(\xi_{i}\right)=\left[q R N\left(\xi_{i}^{L}\right), q R N\left(\xi_{i}^{\prime}\right)\right]=\left(\left[q \xi_{i}^{L}, q \xi_{i}^{U}\right],\left[q \xi_{i}^{L}, q \xi_{i}^{\prime}\right]\right) ; \\
& \operatorname{pIRN}\left(\xi_{i}\right)+q \operatorname{IRN}\left(\xi_{j}\right)=\left(\left[p \xi_{i}^{L}+q \xi_{j}^{L}, p \xi_{i}^{U}+q \xi_{j}^{U}\right],\left[p \xi_{i}^{L}+q \xi_{j}^{L}, p \xi_{i}^{\prime U}+q \xi_{j}^{\prime U}\right]\right) \\
& \left(p \operatorname{IRN}\left(\xi_{i}\right)+q \operatorname{IRN}\left(\xi_{j}\right)\right)^{\frac{w_{i} w_{j}}{1-w_{i}}}=\left[\left[p \xi_{i}^{L}+q \xi_{j}^{L}, p \xi_{i}^{U}+q \xi_{j}^{U}\right]^{\frac{w_{i} w_{j}}{1-w_{i}}},\left[p \xi_{i}^{\prime L}+q \xi_{j}^{L}, p \xi_{i}^{\prime U}+q \xi_{j}^{\prime}\right]^{\frac{w_{i} w_{j}}{1-w_{i}}}\right] \\
& \frac{1}{p+q} \prod_{\substack{i, j=1 \\
i \neq j}}^{n}\left(p \operatorname{IRN}\left(\xi_{i}\right)+q \operatorname{IRN}\left(\xi_{j}\right)\right)^{\frac{w_{i} w_{j}}{1-w_{i}}}= \\
& =\left(\begin{array}{l}
{\left[\frac{1}{p+q} \prod_{\substack{i, j=1 \\
i \neq j}}^{n}\left(p \xi_{i}^{L}+q \xi_{j}^{L}\right)^{\frac{w_{i} w_{j}}{1-w_{i}}}, \frac{1}{p+q} \prod_{\substack{i, j=1 \\
i \neq j}}^{n}\left(p \xi_{i}^{U}+q \xi_{j}^{U}\right)^{\frac{w_{i} w_{j}}{1-w_{i}}}\right],} \\
{\left[\frac{1}{p+q} \prod_{\substack{i, j=1 \\
i \neq j}}^{n}\left(p \xi_{i}^{L}+q \xi_{j}^{\prime L}\right)^{\frac{w_{i} w_{j}}{1-w_{i}}}, \frac{1}{p+q} \prod_{\substack{i, j=1 \\
i \neq j}}^{n}\left(p \xi_{i}^{U}+q \xi_{j}^{U}\right)^{\frac{w_{i} w_{j}}{1-w_{i}}}\right]}
\end{array}\right)
\end{aligned}
$$

So, Theorem 1 is true.

Theorem 2 (Idempotency). Set $\operatorname{IRN}\left(\xi_{i}\right)=\left[R N\left(\xi_{i}^{L}\right), R N\left(\xi_{i}^{U}\right)\right]=\left(\left[\xi_{i}^{L}, \xi_{i}^{U}\right],\left[\xi_{i}^{\prime L}, \xi_{i}^{\prime}\right]\right)(i=1,2, . ., n)$ as a collection of IRNs in $\Psi$, if $\operatorname{IRN}\left(\xi_{i}\right)=\operatorname{IRN}(\xi)$, then

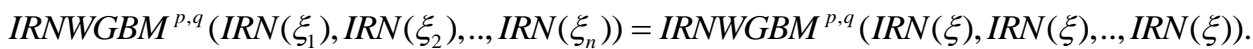


Proof. Since $\operatorname{IRN}\left(\xi_{i}\right)=\operatorname{IRN}(\xi)$, i.e. $\xi_{i}^{L}=\xi^{L}, \xi_{i}^{U}=\xi^{U}, \xi_{i}{ }^{L}=\xi^{L}$ and $\xi_{i}^{\prime}=\xi^{U}$ for $i=1,2, . ., n$, then $\operatorname{IRNWGBM} M^{p, q}\left(\operatorname{IRN}\left(\xi_{1}\right), \operatorname{IRN}\left(\xi_{2}\right), \ldots, \operatorname{IRN}\left(\xi_{n}\right)\right)=\frac{1}{p+q} \prod_{\substack{i, j=1 \\ i \neq j}}^{n}\left(p \operatorname{IRN}\left(\xi_{i}\right)+q \operatorname{IRN}\left(\xi_{j}\right)\right)^{\frac{w_{i} w_{j}}{1-w_{i}}}=$

$=\left(\left[\frac{1}{p+q} \prod_{\substack{i, j=1 \\ i \neq j}}^{n}\left(p \xi_{i}^{L}+q \xi_{j}^{L}\right)^{\frac{w_{i} w_{j}}{1-w_{i}}}, \frac{1}{p+q} \prod_{\substack{i, j=1 \\ i \neq j}}^{n}\left(p \xi_{i}^{U}+q \xi_{j}^{U}\right)^{\frac{w_{i} w_{j}}{1-w_{i}}}\right],\left[\frac{1}{p+q} \prod_{\substack{i, j=1 \\ i \neq j}}^{n}\left(p \xi_{i}^{L}+q \xi_{j}^{L}\right)^{\frac{w_{i} w_{j}}{1-w_{i}}}, \frac{1}{p+q} \prod_{\substack{i, j=1 \\ i \neq j}}^{n}\left(p \xi_{i}^{U}+q \xi_{j}^{U}\right)^{\frac{w_{i}, w_{j}}{1-w_{i}}}\right]\right)$ $=\left(\left[\frac{1}{p+q} \prod_{\substack{i, j=1 \\ i \neq j}}^{n}\left(p \xi^{L}+q \xi^{L}\right)^{\frac{w_{i} w_{j}}{1-w_{i}}}, \frac{1}{p+q} \prod_{\substack{i, j=1 \\ i \neq j}}^{n}\left(p \xi^{U}+q \xi^{U}\right)^{\frac{w_{i} w_{j}}{1-w_{i}}}\right],\left[\frac{1}{p+q} \prod_{\substack{i, j=1 \\ i \neq j}}^{n}\left(p \xi^{L}+q \xi^{L}\right)^{\frac{w_{i} w_{j}}{1-w_{i}}}, \frac{1}{p+q} \prod_{\substack{i, j=1 \\ i \neq j}}^{n}\left(p \xi^{U}+q \xi^{U}\right)^{\frac{w_{i} w_{j}}{1-w_{i}}}\right]\right)$ $=\left(\left[\frac{1}{p+q} \prod_{\substack{i, j=1 \\ i \neq j}}^{n}\left(\xi^{L}(p+q)\right)^{\frac{1}{i-w_{i}}}, \frac{1}{p+q} \prod_{\substack{i, j=1 \\ i \neq j}}^{n}\left(\xi^{U}(p+q)\right)^{\frac{w_{i} w_{j}}{1-w_{i}}}\right],\left[\frac{1}{p+q} \prod_{\substack{i, j=1 \\ i \neq j}}^{n}\left(\xi^{L}(p+q)\right)^{\frac{1}{1-w_{i} w_{j}}}, \frac{1}{p+q} \prod_{\substack{i, j=1 \\ i \neq j}}^{n}\left(\xi^{U}(p+q)\right)^{\frac{w_{i} w_{j}}{1-w_{i}}}\right]\right)$ $=\left(\left[\prod_{\substack{i, j=1 \\ i \neq j}}^{n}\left(\xi^{L}\right)^{\frac{w_{i} w_{j}}{1-w_{i}}}, \prod_{\substack{i, j=1 \\ i \neq j}}^{n}\left(\xi^{U}\right)^{\frac{w_{i} w_{j}}{1-w_{i}}}\right],\left[\prod_{\substack{i, j=1 \\ i \neq j}}^{n}\left(\xi^{L}\right)^{\frac{w_{i} w_{j}}{1-w_{i}}}, \prod_{\substack{i, j=1 \\ i \neq j}}^{n}\left(\xi^{U}\right)^{\frac{w_{i} w_{j}}{1-w_{i}}}\right]\right)$ $=\left(\left[\xi^{L}, \xi^{U}\right],\left[\xi^{L}, \xi^{U}\right]\right)=\left[R N\left(\xi^{L}\right), R N\left(\xi^{U}\right)\right]=\operatorname{IRN}(\xi)$

The proof of Theorem 2 is completed.

Theorem 3 (Boundedness). Let $\operatorname{IRN}\left(\xi_{i}\right)=\left[R N\left(\xi_{i}^{L}\right), R N\left(\xi_{i}^{U}\right)\right]=\left(\left[\xi_{i}^{L}, \xi_{i}^{U}\right],\left[\xi_{i}^{\prime L}, \xi_{i}^{\prime}\right]\right)(i=1,2, . ., n)$ as a collection of IRNs in $\Psi$, let

$$
\begin{aligned}
& \operatorname{IRN}\left(\xi^{-}\right)=\left(\left[\min \xi^{L}, \min \xi^{U}\right],\left[\min \xi^{L}, \min \xi^{\prime}\right]\right) \text { and } \\
& \operatorname{IRN}\left(\xi^{+}\right)=\left(\left[\max \xi^{L}, \max \xi^{U}\right],\left[\max \xi^{L}, \max \xi^{\prime}\right]\right) \text {, then }
\end{aligned}
$$

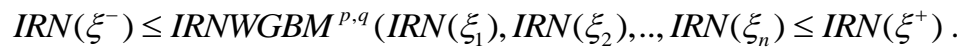

Proof. Let and

$$
\operatorname{IRN}(\xi)=\min \left(\operatorname{IRN}\left(\xi_{1}\right), \operatorname{IRN}\left(\xi_{2}\right), \ldots, \operatorname{IRN}\left(\xi_{n}\right)\right)=\left(\left[\min \xi_{i}{ }^{L}, \min \xi_{i}{ }^{U}\right],\left[\min \xi_{i}{ }^{L}, \min \xi_{i}{ }^{\prime}\right]\right)
$$

$\operatorname{IRN}\left(\xi^{+}\right)=\max \left(\operatorname{IRN}\left(\xi_{1}\right), \operatorname{IRN}\left(\xi_{2}\right), \ldots, \operatorname{IRN}\left(\xi_{n}\right)\right)=\left(\left[\max \xi_{i}^{L}, \max \xi_{i}^{U}\right],\left[\max \xi_{i}{ }^{L}, \max _{i}{ }^{\prime}{ }^{U}\right]\right)$. then we have $\min \xi_{i}^{L}=\min \left(\xi_{i}^{L}\right), \min \xi_{i}^{U}=\min \left(\xi_{i}{ }^{U}\right), \min \xi_{i}{ }^{L}=\min \left(\xi_{i}{ }^{\prime}\right), \min \xi_{i}^{\prime}{ }^{\prime}=\min \left(\xi_{i}^{\prime} U\right)$, $\max \xi_{i}^{L}=\max \left(\xi_{i}^{L}\right), \max \xi_{i}^{U}=\max \left(\xi_{i}^{U}\right), \max \xi_{i}{ }^{\prime}=\max \left(\xi_{i}{ }^{\prime}\right)$ and $\max \xi_{i}^{\prime}=\max \left(\xi_{i}^{\prime}{ }^{U}\right)$. Based on that we have

$$
\begin{aligned}
& \operatorname{IRN}\left(\xi^{-}\right) \leq \operatorname{IRN}\left(\xi_{i}\right) \leq \operatorname{IRN}\left(\xi^{+}\right) \\
& \min \left(\xi_{i}^{L}\right) \leq \xi_{i}^{L} \leq \max \left(\xi_{i}^{L}\right) ; \\
& \min \left(\xi_{i}^{U}\right) \leq \xi_{i}^{U} \leq \max \left(\xi_{i}^{U}\right) ; \\
& \min \left(\xi_{i}^{L}\right) \leq \xi_{i}^{L} \leq \max \left(\xi_{i}^{\prime L}\right) ; \\
& \min \left(\xi_{i}^{U}\right) \leq \xi_{i}^{\prime} \leq \max \left(\xi_{i}^{\prime}\right) ;
\end{aligned}
$$

According to the inequalities showed above, we can conclude that $\operatorname{IRN}(\xi) \leq$ $\operatorname{IRNWGBM} M^{p, q}\left(\operatorname{IRN}\left(\xi_{1}\right), \operatorname{IRN}\left(\xi_{2}\right), \ldots, \operatorname{IRN}\left(\xi_{n}\right)\right) \leq \operatorname{IRN}\left(\xi^{+}\right)$holds. 
Theorem 4 (Commutativity). Let rough set $\left(\operatorname{IRN}\left(\xi_{1}^{\prime}\right), \operatorname{IRN}\left(\xi_{2}^{\prime}\right), \ldots, \operatorname{IRN}\left(\xi_{n}^{\prime}\right)\right)$ be any permutation of $\left(\operatorname{IRN}\left(\xi_{1}\right), \operatorname{IRN}\left(\xi_{2}\right), \ldots, \operatorname{IRN}\left(\xi_{n}\right)\right)$. Then there is

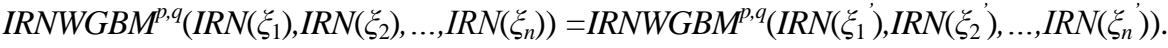

Proof. The property is obvious.

\section{IRN DEMATEL-COPRAS MODEL}

\subsection{Extension of the DEMATEL method based on interval rough numbers}

Using the DEMATEL method, the dependent factors are considered and the degree of dependency between them is determined [32]. The method is based on the graph theory and enables visual planning and problem solving. This method allows better understanding of the relationship between factors, the relationship between the level of structure and the strength of factor influence $[33,34]$. As the result of the method application, total direct and indirect effects of every factor upon other factors as well as those received from other factors are obtained.

In order to comprehensively consider imprecision and uncertainty existing in group decision-making, in this paper the modification of the DEMATEL method is performed by using interval rough numbers. Their use eliminates the need for additional information in order to determine uncertain number intervals [34]. So far, in the literature the modification of the DEMATEL method by applying interval rough numbers (IR'DEMATEL) for determining interval rough coefficients of weight criteria has not been considered. In the following part, the steps of the IR'DEMATEL method are elaborated:

Step 1: Expert analysis of factors. Assuming that there are $m$ experts and $n$ factors which are considered, every expert should determine the degree of influence of factor $i$ on factor $j$. A comparative analysis of the pair of $i$-th and $j$-th factor by $e$-th expert is marked with $x_{i j}{ }^{e}$, where: $i=1, \ldots, n ; j=1, \ldots, n$. The value of every pair $x_{i j}{ }^{e}$ has one whole number value with the following meaning: 0 - no influence; 1 - low influence; 2 - middle influence; 3 - high influence; 4 - very high influence. The response of the $e$-th expert is shown with nonnegative matrix of the range $n \times n$, and every element of the $e$-th matrix in the expression $X^{e}=\left[x_{i j}^{e}\right]_{n \times n}$ marks the whole nonnegative number $x_{i j}^{e}$, where $1 \leq e \leq b$.

$$
X^{e}=\left[\begin{array}{cccc}
0 & x_{12}^{e} ; x_{12}^{e^{\prime}} & \cdots & x_{1 n}^{e} ; x_{1 n}^{e^{\prime}} \\
x_{21}^{e} ; x_{21}^{e^{\prime}} & 0 & \cdots & x_{2 n}^{e} ; x_{2 n}^{e^{\prime}} \\
\vdots & \vdots & \ddots & \vdots \\
x_{n 1}^{e} ; x_{n 1}^{e^{\prime}} & x_{n 2}^{e} ; x_{n 2}^{e^{\prime}} & \cdots & 0
\end{array}\right]_{n x n} ; 1 \leq i, j \leq n ; 1 \leq e \leq b
$$

where $x_{i j}{ }^{e}$ and $x_{i j} e^{\prime}$ present linguistic expressions from the predefined linguistic scale by which expert $e$ presents his comparison in the pairs of criteria.

Therefore, matrices $X^{1}, X^{2}, \ldots, X^{m}$ are those of the response of every of $b$ experts. The diagonal matrix elements of the responses of all experts have the value zero because the same factors have no influence.

If expert $e$ has uncertainty during a pair comparison of criteria $(i, j)$, that is, if expert $e$ cannot decide between two values from the linguistic scale, then both values from the 
scale are stated in matrix $X^{e}$. Then, at the position $(i, j)$ in matrix $X^{e}$ we have different values of $x_{i j}^{e}$, that is, $x_{i j}^{e} \neq x^{e^{e}}{ }_{i j}$. If there is no uncertainty, expert $e$ unequivocally selects one value. Then, in the matrix of the comparison of criteria $\left(X^{e}\right)$ is entered the same value at the position $(i, j)$, that is $x_{i j}^{e}=x^{e^{e}}{ }_{i j}$.

Step 2: Determination of the matrix of average responses of experts. Based on the matrices of the responses $X^{e}=\left[x_{i j}^{e}\right]_{n \times n}$ of all $m$ experts, by applying Eqs. (1-11) are determined classes of objects and defined interval rough numbers in matrices $X^{1}, X^{2}, \ldots$, $X^{b}$. That is how interval rough matrices $X^{e}(i=1,2, \ldots, b)$ are obtained and presented in the form

$$
X_{e}=\left[\begin{array}{cccc}
0 & \operatorname{IRN}\left(x_{i j}^{e}\right) & \cdots & \operatorname{IRN}\left(x_{i j}^{e}\right) \\
\operatorname{IRN}\left(x_{i j}^{e}\right) & 0 & \cdots & \operatorname{IRN}\left(x_{i j}^{e}\right) \\
\vdots & \vdots & \ddots & \vdots \\
\operatorname{IRN}\left(x_{i j}^{e}\right) & \operatorname{IRN}\left(x_{i j}^{e}\right) & \cdots & 0
\end{array}\right]
$$

where $e(e=1,2, \ldots, b)$ presents the mark (number) of the expert, and $\operatorname{IRN}\left(x_{i j}^{e}\right)$ presents the interval rough number presented in the form $\operatorname{IRN}\left(x_{i j}^{e}\right)=\left[R N\left(x_{i j}^{e L}\right), R N\left(x_{i j}{ }^{e}{ }^{\prime}\right)\right]=\left(\left[x_{i j}{ }^{e L}, x_{i j}^{e U}\right]\right.$, $\left.\left[x_{i j}^{e^{\prime} L}, x_{i j}^{e^{\prime} U}\right]\right)$.

By applying the IRNWGBM operator, Eq. (14), we obtain averaged interval rough number $\operatorname{IRN}\left(x_{i j}^{e}\right)=\left[R N\left(x_{i j}^{e L}\right), R N\left(x_{i j}^{e^{\prime} U}\right)\right]$.

In this way we obtain averaged rough matrix of average responses $Z$

$$
Z=\left[\begin{array}{cccc}
0 & \operatorname{IRN}\left(z_{12}\right) & \cdots & \operatorname{IRN}\left(z_{1 n}\right) \\
\operatorname{IRN}\left(z_{21}\right) & 0 & \cdots & \operatorname{IRN}\left(z_{2 n}\right) \\
\vdots & \vdots & \ddots & \vdots \\
\operatorname{IRN}\left(z_{n 1}\right) & \operatorname{IRN}\left(z_{n 2}\right) & \cdots & 0
\end{array}\right]
$$

Step 3: Based on matrix $Z$ initial direct-relation matrix $D=\left[\operatorname{IRN}\left(d_{i j}\right)\right]_{n \times n}$ is calculated, see Eq. (18). By normalization every element of matrix $D$ takes the value between zero and one. Matrix $D$ is obtained when every element $\operatorname{IRN}\left(z_{i j}\right)$ of matrix $Z$ is divided by rough number $I R N(s)$, see Eqs. (18)-(20)

$$
D=\left[\begin{array}{cccc}
0 & \operatorname{IRN}\left(d_{12}\right) & \cdots & \operatorname{IRN}\left(d_{1 n}\right) \\
\operatorname{IRN}\left(d_{21}\right) & 0 & \cdots & \operatorname{IRN}\left(d_{2 n}\right) \\
\vdots & \vdots & \ddots & \vdots \\
\operatorname{IRN}\left(d_{n 1}\right) & \operatorname{IRN}\left(d_{n 2}\right) & \cdots & 0
\end{array}\right]
$$

where $I R N\left(d_{i j}\right)$ is obtained by applying Eq. (18)

$$
\operatorname{IRN}\left(d_{i j}\right)=\frac{\operatorname{IRN}\left(z_{i j}\right)}{\operatorname{IRN}(s)}=\operatorname{IRN}\left(\left[\frac{z_{i j}^{L}}{s_{i j}^{U}}, \frac{z_{i j}^{U}}{s_{i j}^{L}}\right],\left[\frac{z_{i j}^{L}}{s_{i j}^{U}}, \frac{z_{i j}^{\prime U}}{z_{i j}^{L}}\right]\right)
$$

The value of interval rough number $I R N(s)$ is obtained by applying Eq. (20) 
$\operatorname{IRN}(s)=\max \left(\left[\max \left\{\sum_{j=1}^{n} x_{i j}^{L}\right\}, \max \left\{\sum_{j=1}^{n} x_{i j}^{U}\right\}\right],\left[\max \left\{\sum_{j=1}^{n} x_{i j}^{L}\right\}, \max \left\{\sum_{j=1}^{n} x_{i j}^{\prime}\right\}\right]\right)$

Step 4: The total relation matrix $\left(T=\left[\operatorname{IRN}\left(t_{i j}\right)\right]_{n \times n}\right)$ of the range $n \times n$ is calculated, according to Eq. (21). Element $I R N\left(t_{i j}\right)$ presents direct influence of factor $i$ on factor $j$, and matrix $T$ shows total relations between every pair of factors.

$$
T=\lim _{m \rightarrow \infty}\left(D+D^{2}+\ldots+D^{m}\right)=\sum_{m=1}^{\infty} D^{i}
$$

where

$$
\begin{aligned}
\sum_{m=1}^{\infty} D^{i} & =D+D^{2}+\ldots+D^{m}= \\
& =D\left(I+D^{1}+D^{2}+\ldots+D^{m-1}\right) \\
& =D(I-D)^{-1}(I-D)\left(I+D^{1}+D^{2}+\ldots+D^{m-1}\right) \\
& =D(I-D)^{-1}\left(I-D^{m}\right) \\
& =D(I-D)^{-1}
\end{aligned}
$$

where $I$ is the unit matrix of the range $n \times n$.

Based on Eqs. (21) and (22), the total relation matrix is obtained:

$$
T=\left[\begin{array}{cccc}
\operatorname{IRN}\left(t_{11}\right) & \operatorname{IRN}\left(t_{12}\right) & \cdots & \operatorname{IRN}\left(t_{1 n}\right) \\
\operatorname{IRN}\left(t_{21}\right) & \operatorname{IRN}\left(t_{22}\right) & \cdots & \operatorname{IRN}\left(t_{2 n}\right) \\
\vdots & \vdots & \ddots & \vdots \\
\operatorname{IRN}\left(t_{n 1}\right) & \operatorname{IRN}\left(t_{n 2}\right) & \cdots & \operatorname{IRN}\left(t_{n n}\right)
\end{array}\right]
$$

where $\operatorname{IRN}\left(t_{i j}\right)=\left[R N\left(t_{i j}{ }^{L}\right), R N\left(\mathrm{t}_{i j}{ }^{\prime} U\right)\right]$ is interval rough number by which indirect effects of factor $i$ on factor $j$ are expressed. Then, matrix $T$ shows mutual dependence of every pair of factors.

Step 5: Calculation of the sum of rows and columns of total relation matrix $T$. In total relation matrix $T$ the sum of rows and sum of columns is presented by vectors $R$ and $C$ with the range $n \times 1$ :

$$
\begin{gathered}
\operatorname{IRN}\left(R_{i}\right)=\left[\sum_{j=1}^{n} \operatorname{IRN}\left(t_{i j}\right)\right]_{n \times 1}=\left[\left(\left[\sum_{j=1}^{n} t_{i j}^{L}, \sum_{j=1}^{n} t_{i j}^{U}\right],\left[\sum_{j=1}^{n} t_{i j}^{L}, \sum_{j=1}^{n} t_{i j}^{\prime U}\right]\right)\right]_{n \times 1} \\
\operatorname{IRN}\left(C_{i}\right)=\left[\sum_{i=1}^{n} \operatorname{IRN}\left(t_{i j}\right)\right]_{1 \times n}=\left[\left(\left[\sum_{i=1}^{n} t_{i j}^{L}, \sum_{i=1}^{n} t_{i j}^{U}\right],\left[\sum_{i=1}^{n} t_{i j}^{L}, \sum_{i=1}^{n} t_{i j}^{U}\right]\right)\right]_{1 \times n}
\end{gathered}
$$

Value $R_{i}$ presents the sum of the $i$-th row of matrix $T$, and shows total direct and indirect effects which criterion $i$ provided to other criteria. Value $C_{i}$ presents the sum of the $j$-th column of matrix $T$, and shows total direct and indirect effects that criterion $j$ received from other criteria [10].

Step 6: Determination of weight coefficients of criteria $\left(w_{i}\right)$. The calculation of weight coefficients of criteria is performed based on the values obtained in step 5, see Eq. (26) 


$$
I R N\left(W_{j}\right)=\left[R N\left(W_{j}^{L}\right), R N\left(W_{j}^{\prime}\right)\right]=\left\{\begin{array}{l}
W_{j}^{L}=\sqrt{\left(R_{i}^{L}+C_{i}^{L}\right)^{2}+\left(R_{i}^{L}-C_{i}^{L}\right)^{2}} \\
W_{j}^{U}=\sqrt{\left(R_{i}^{U}+C_{i}^{U}\right)^{2}+\left(R_{i}^{U}-C_{i}^{U}\right)^{2}} \\
W_{j}^{\prime L}=\sqrt{\left(R_{i}^{\prime L}+C_{i}^{\prime L}\right)^{2}+\left(R_{i}^{L}-C_{i}^{\prime L}\right)^{2}} \\
W_{j}^{\prime}=\sqrt{\left(R_{i}^{\prime}+C_{i}^{\prime}\right)^{2}+\left(R_{i}^{\prime U}-C_{i}^{\prime U}\right)^{2}}
\end{array}\right.
$$

where the values $R_{i}+C_{i}$ and $R_{i}-C_{i}$ are obtained by applying Eqs. (27) and (28)

$$
\begin{aligned}
& \operatorname{IRN}\left(R_{i}\right)+\operatorname{IRN}\left(C_{i}\right)=\left[\begin{array}{l}
{\left[\sum_{j=1}^{n} t_{i j}^{L}+\sum_{i=1}^{n} t_{i j}^{L}, \sum_{j=1}^{n} t_{i j}^{U}+\sum_{i=1}^{n} t_{i j}^{U}\right],} \\
{\left[\sum_{j=1}^{n} t_{i j}^{L}+\sum_{i=1}^{n} t_{i j}^{L}, \sum_{j=1}^{n} t_{i j}^{U}+\sum_{i=1}^{n} t_{i j}^{U}\right]}
\end{array}\right] \\
& \operatorname{IRN}\left(R_{i}\right)-\operatorname{IRN}\left(C_{i}\right)=\left[\begin{array}{l}
{\left[\sum_{j=1}^{n} t_{i j}^{L}-\sum_{i=1}^{n} t_{i j}^{U}, \sum_{j=1}^{n} t_{i j}^{U}-\sum_{i=1}^{n} t_{i j}^{L}\right]} \\
{\left[\sum_{j=1}^{n} t_{i j}^{L}-\sum_{i=1}^{n} t_{i j}^{U}, \sum_{j=1}^{n} t_{i j}^{U}-\sum_{i=1}^{n} t_{i j}^{L}\right]}
\end{array}\right]
\end{aligned}
$$

The normalization of weight coefficients is performed by applying Eq. (29)

$$
\operatorname{IRN}\left(w_{j}\right)=\frac{\operatorname{IRN}\left(W_{j}\right)}{\sum_{j=1}^{n} \operatorname{IRN}\left(W_{j}\right)}=\left(\left[\frac{W_{j}^{L}}{\sum_{j=1}^{n} W_{j}^{U}}, \frac{W_{j}^{U}}{\sum_{j=1}^{n} W_{j}^{\prime L}}\right],\left[\frac{W_{j}^{\prime L}}{\sum_{j=1}^{n} W_{j}^{U}}, \frac{W_{j}^{\prime}}{\sum_{j=1}^{n} W_{j}^{L}}\right]\right)
$$

where $n$ denotes the number of the evaluation criteria, $\operatorname{IRN}\left(w_{i}\right)$ final values of weight coefficients which are used in the decision-making process.

\subsection{Extension of the COPRAS method based on interval rough numbers}

Every MCDM method is characterized by specific mathematical apparatus. The COPRAS method is characterized by a somewhat more complex aggregation process of the values of criteria functions and a simplified procedure for data normalization (the character of criteria is not considered - $\min / \max$ ). In the following part, the mathematical apparatus of the COPRAS method is briefly presented.

Step 1: A group of experts $(e=1,2, \ldots, b)$ is formed where $b$ presents the number of experts who select the criteria and define the elements of the initial decision-making matrix. The problem is formally presented by the selection of one of $m$ options (alternatives), $A_{i}, i=1,2, \ldots, m$, which are evaluated and compared mutually based on $n$ criteria $\left(X_{j}, j=1,2, \ldots, n\right)$ whose values we know. The alternatives are shown with vectors $x_{i j}^{e} ; x^{e^{*}}{ }_{i j}$, where $x_{i j}^{e} ; x^{e^{*}}{ }_{i j}$ presents the value of the $i$-th alternative by $j$-th criterion.

Based on Eqs. (1)-(11), the evaluations of experts by vectors $x_{i j}$ are transformed into interval rough vectors $A_{i}=\left(\operatorname{IRN}\left(x_{i 1}\right), \operatorname{IRN}\left(x_{i 2}\right), \ldots, \operatorname{IRN}\left(x_{i n}\right)\right)$, where $\operatorname{IRN}\left(x_{i j}\right)=$ $\left[R N\left(x_{i j}{ }^{L}\right), R N\left(x_{i j}{ }^{\prime}\right)\right]=\left(\left[x_{i j}{ }^{L}, x_{i j}{ }^{U}\right],\left[x_{i j}{ }^{L}, x_{i j}{ }^{\prime}\right]\right)$ presents the value of the $i$-th alternative by $j$-th criterion $(i=1,2, \ldots, m ; j=1,2, \ldots, n)$. Since the criteria affect differently final values of alternatives, to every criterion is attributed weight coefficient $w_{j}, j=1,2, \ldots, n$ which reflects its relative significance in the evaluation of alternatives. 
In that way matrices $X_{e}=\mathrm{X}_{1}, X_{2}, \ldots, X_{b} \quad(e=1,2, \ldots, b)$ are obtained in which $b$ experts performed the comparison in pairs of criteria.

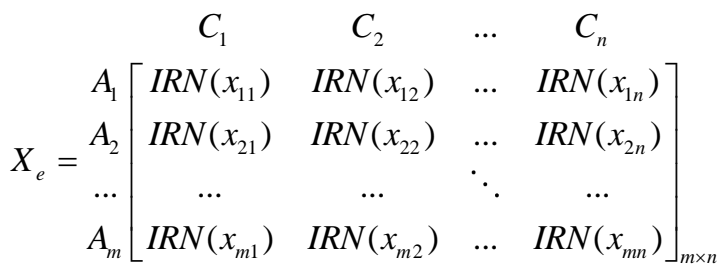

where $m$ is the number of alternatives, and $n$ is total number of criteria.

Step 2: Normalization of the initial decision-making matrix $\left(X_{e}\right)$. Basic objective of the normalization of criteria values is the transformation of different values of criteria (benefit or cost) into the values allowing mutual comparison. By applying the IRNWGBM operator, from Eq. (14), averaged interval rough number $\operatorname{IRN}\left(x_{i j}\right)=\left[R N\left(x_{i j}{ }^{L}\right), R N\left(x_{i j}{ }^{\prime} U\right)\right]$ is obtained which is further normalized in matrix $D$. Normalized values are shown in matrix $D$

$$
\begin{aligned}
& \begin{array}{cccc}
C_{1} & C_{2} & \ldots & C_{n}
\end{array} \\
& D=\begin{array}{c}
A_{1} \\
A_{2} \\
\ldots \\
A_{m}
\end{array}\left[\begin{array}{cccc}
\operatorname{IRN}\left(d_{11}\right) & \operatorname{IRN}\left(d_{12}\right) & \ldots & \operatorname{IRN}\left(d_{1 n}\right) \\
\operatorname{IRN}\left(d_{21}\right) & \operatorname{IRN}\left(d_{22}\right) & \ldots & \operatorname{IRN}\left(d_{2 n}\right) \\
\ldots & \ldots & \ddots & \ldots \\
\operatorname{IRN}\left(d_{m 1}\right) & \operatorname{IRN}\left(d_{m 2}\right) & \ldots & \operatorname{IRN}\left(d_{m n}\right)
\end{array}\right]_{m \times n}
\end{aligned}
$$

The elements of normalized matrix $\operatorname{IRN}\left(d_{i j}\right)$ are obtained by applying the expression

$$
\operatorname{IRN}\left(d_{i j}\right)=\left(\left[d_{i j}^{L}, d_{i j}^{U}\right],\left[d_{i j}^{\prime L}, d_{i j}^{\prime U}\right]\right)=\frac{\operatorname{IRN}\left(x_{i j}\right)}{\sum_{i=1}^{m} \operatorname{IRN}\left(x_{i j}\right)}=\frac{\left(\left[x_{i j}^{L}, x_{i j}^{U}\right],\left[x_{i j}^{\prime L}, x_{i j}^{\prime}\right]\right)}{\left(\left[\sum_{i=1}^{m} x_{i j}^{L}, \sum_{i=1}^{m} x_{i j}^{U}\right],\left[\sum_{i=1}^{m} x_{i j}^{\prime L}, \sum_{i=1}^{m} x_{i j}^{\prime}\right]\right)}
$$

where $\operatorname{IRN}\left(x_{i j}\right)$ presents the elements of the initial decision-making matrix $\left(X_{e}\right), \operatorname{IRN}\left(d_{i j}\right)$ presents normalized values of the elements of the initial decision-making matrix, $m$ presents total number of alternatives.

Step 3: In the third step the weighted normalized matrix $(Z)$ is formed in which the elements of normalized matrix $(D)$ are multiplied by weights of criteria $\left(\operatorname{IRN}\left(w_{j}\right)\right)$

$$
Z=\left[\begin{array}{cccc}
\operatorname{IRN}\left(z_{11}\right) & \operatorname{IRN}\left(z_{12}\right) & \ldots & \operatorname{IRN}\left(z_{1 n}\right) \\
\operatorname{IRN}\left(z_{21}\right) & \operatorname{IRN}\left(z_{22}\right) & \ldots & \operatorname{IRN}\left(z_{2 n}\right) \\
\ldots & \ldots & \ddots & \ldots \\
\operatorname{IRN}\left(z_{m 1}\right) & \operatorname{IRN}\left(z_{m 2}\right) & \ldots & \operatorname{IRN}\left(z_{m n}\right)
\end{array}\right]
$$

where the elements of matrix $Z$ are obtained by multiplying normalized elements of the matrix given in Eq. (31) by weight coefficients of criteria $\operatorname{IRN}\left(w_{j}\right)$, respectively, $\operatorname{IRN}\left(z_{i j}\right)=$ $\operatorname{IRN}\left(d_{i j}\right) * \operatorname{IRN}\left(w_{j}\right)$. 
Step 4: In the following or fourth step, are summed the values of matrix $Z$ by columns. The values are summed up depending on the group of criteria they belong to ( $\mathrm{min}$ or max). The values of $\max$ criteria (higher values of criteria are desirable) are obtained by the application of Eq. (34), respectively, Eq. (35)

$$
\operatorname{IRN}\left(S_{i}^{+}\right)=\sum_{z_{i}=+} \operatorname{IRN}\left(z_{i j}\right)
$$

where $z_{i}=+$ presents the set of $\max$ criteria, respectively,

$$
\operatorname{IRN}\left(S_{i}^{+}\right)=\sum_{i=1}^{k} \operatorname{IRN}\left(d_{i j}\right) \cdot \operatorname{IRN}\left(w_{j}\right)
$$

where $k$ presents the total number of $\max$ criteria.

The values of $\min$ criteria (lower values of criteria are desirable) are obtained by applying Eq. (36), respectively, Eq. (37)

$$
\operatorname{IRN}\left(S_{i}^{-}\right)=\sum_{z_{i}=-} \operatorname{IRN}\left(z_{i j}\right)
$$

where $z_{i}=-$ presents the set of $\min$ criteria, respectively,

$$
\operatorname{IRN}\left(S_{i}^{-}\right)=\sum_{i=1}^{p} \operatorname{IRN}\left(d_{i j}\right) \cdot \operatorname{IRN}\left(w_{j}\right)
$$

where $p$ presents total number of $\min$ criteria

Step 5: In the fifth step by applying Eq. (38) the relevance (influence) of every observed alternative from the set of alternatives being compared is determined.

$$
\begin{aligned}
& \operatorname{IRN}\left(Q_{i}\right)=\operatorname{IRN}\left(S_{i}^{+}\right)+\frac{\operatorname{IRN}\left(S_{\mathrm{min}}^{-}\right) \sum_{i=1}^{m} \operatorname{IRN}\left(S_{i}^{-}\right)}{\operatorname{IRN}\left(S_{i}^{-}\right) \sum_{i=1}^{m}\left(\frac{\operatorname{IRN}\left(S_{\text {min }}^{-}\right)}{\operatorname{IRN}\left(S_{i}^{-}\right)}\right)}= \\
& \operatorname{IRN}\left(S_{i}^{+}\right)+\frac{\sum_{i=1}^{m} \operatorname{IRN}\left(S_{i}^{-}\right)}{\operatorname{IRN}\left(S_{i}^{-}\right) \sum_{i=1}^{m} \frac{1}{\operatorname{IRN}\left(S_{i}^{-}\right)}}
\end{aligned}
$$

Step 6: In the last or sixth step, the alternatives are ranged based on the values of criteria functions which are assigned to every alternative, where as the most desirable alternative is selected the one with the highest value of criteria function.

\section{APPLICATION OF THE NWGBM OPERATOR IN THE IR'DEMATEL-COPRAS MODEL}

The IR'DEMATEL-COPRAS model with the NWGBM operator was tested on the problem of selecting an optimal direction for making a temporary military route. The temporary military route represents a type of route with limited duration [39]. These routes are mostly used for a short time, usually during combat operations, sometimes for disposable use. They are built on the directions of the movement of units in situations 
where the existing roads are insufficient or highly damaged [39]. Such roads are built for taking position, supply, when the existing roads or road network is to be circumvented or because of certain objects - settlements located on the existing roads, etc. The existing literature elaborates the methodology for defining direction of the temporary military route taking into account primarily the length of route and the scope of works. Other segments, which have a significant influence, are usually not elaborated. For this reason, the criteria that influence the selection of the temporary route direction are further elaborated in Table 1.

Table 1 Criteria for selecting the temporary route direction

\begin{tabular}{|c|c|}
\hline Name of criterion & Description of criterion \\
\hline Scope of works (C1) & $\begin{array}{l}\text { This criterion defines the scope of works necessary for the construction of a } \\
\text { particular road section. The scope of works depends on the type of soil and } \\
\text { its carrying capacity, in relation to the maximum type of load planned for } \\
\text { transport via the route considered. The criterion is presented through } \\
\text { qualitative parameters and belongs to the group of min criteria. }\end{array}$ \\
\hline Critical points (C2) & $\begin{array}{l}\text { Through this criterion a number of potential regions is defined, where it is } \\
\text { possible for an enemy with significant prospects of success to set an ambush. The } \\
\text { criterion is of quantitative character and belongs to the group of min criteria. }\end{array}$ \\
\hline Length of route $(\mathrm{C} 3)$ & $\begin{array}{l}\text { This criterion defines the length of route, which further affects the time } \\
\text { when the units are retained on it. This increases or decreases the security of } \\
\text { the people and means using a temporary military route. The criterion is of } \\
\text { quantitative character and belongs to the group of min criteria. }\end{array}$ \\
\hline $\begin{array}{l}\text { Masking the } \\
\text { movement (C4) }\end{array}$ & $\begin{array}{l}\text { In this criterion, through linguistic descriptions are defined the possibilities of } \\
\text { masking the movement of units while moving on a temporary military route. The } \\
\text { criterion is described by linguistic values and belongs to the group of max criteria. }\end{array}$ \\
\hline $\begin{array}{l}\text { Capacities for } \\
\text { reparation and } \\
\text { reconstruction of } \\
\text { route }(\text { C5) }\end{array}$ & $\begin{array}{l}\text { Capacities necessary for reparation and reconstruction of the route. For the } \\
\text { purpose of quantification of this criterion, a working group of components is } \\
\text { defined including: grader, dozer, roller, loader and two self-loaders. The } \\
\text { evaluation of the criteria is based on the required number of working groups } \\
\text { it and belongs to the group of min criteria. }\end{array}$ \\
\hline $\begin{array}{l}\text { Capacities for } \\
\text { providing supply, } \\
\text { respectively, the } \\
\text { movement of units on } \\
\text { the route made (C6) }\end{array}$ & $\begin{array}{l}\text { These units monitor the movement of own forces, as well as the activities of } \\
\text { the enemy. With their presence, they should prevent attacks on the vehicles } \\
\text { moving along the way. The basic unit that quantifies this criterion is the } \\
\text { shooting unit. The evaluation of the criteria is based on the required number } \\
\text { of shooting units and it belongs to the group of min criteria. }\end{array}$ \\
\hline
\end{tabular}


The application of the hybrid IR'DEMATEL-COPRAS model with the NWGBM operator is shown on the example of the evaluation of six routes for the construction of a temporary military route in southern Serbia. The routes considered are marked with A1 to A6. In the first phase of the IR'DEMATEL-COPRAS model, the weight coefficients of the criteria are calculated using the IR'DEMATEL model.In the first step of the IR'DEMATEL model, an expert analysis of the factors is performed. In this research, three experts took part in the evaluation of the criteria using the scale: 0 - no influence; 1 - low influence; 2 - middle influence; 3 - high influence; 4 - very high influence; 5 -extremely high influence. The weight coefficients of the experts were determined $(0.337,0.314,0.349)^{T}$. After the expert evaluation, three matrices of comparisons were obtained in pairs of criteria with the dimension $6 \times 6$, (Table 2 ).

Table 2 Expert evaluation of criteria

\begin{tabular}{ccccccc}
\hline \multicolumn{7}{c}{ Expert 1} \\
\hline & C1 & C2 & C3 & C4 & C5 & C6 \\
\hline C1 & $0 ; 0$ & $3 ; 4$ & $4 ; 5$ & $5 ; 5$ & $3 ; 4$ & $4 ; 4$ \\
C2 & $4 ; 5$ & $0 ; 0$ & $3 ; 4$ & $4 ; 4$ & $5 ; 5$ & $5 ; 5$ \\
C3 & $2 ; 3$ & $1 ; 2$ & $0 ; 0$ & $4 ; 4$ & $3 ; 4$ & $4 ; 5$ \\
C4 & $2 ; 2$ & $3 ; 3$ & $4 ; 5$ & $0 ; 0$ & $4 ; 4$ & $3 ; 4$ \\
C5 & $2 ; 3$ & $2 ; 2$ & $2 ; 3$ & $1 ; 2$ & $0 ; 0$ & $5 ; 5$ \\
C6 & $3 ; 4$ & $2 ; 3$ & $2 ; 3$ & $3 ; 4$ & $2 ; 3$ & $0 ; 0$ \\
\hline \multicolumn{7}{c}{ Expert 2} \\
\hline C1 & C1 & C2 & C3 & C4 & C5 & C6 \\
\hline C2 & $5 ; 5$ & $4 ; 5$ & $5 ; 5$ & $5 ; 5$ & $5 ; 5$ & $5 ; 5$ \\
C3 & $2 ; 3$ & $3 ; 4$ & $4 ; 5$ & $4 ; 4$ & $4 ; 4$ & $5 ; 5$ \\
C4 & $3 ; 4$ & $3 ; 4$ & $3 ; 4$ & $0 ; 0$ & $4 ; 5$ & $4 ; 5$ \\
C5 & $2 ; 3$ & $1 ; 2$ & $3 ; 4$ & $2 ; 3$ & $0 ; 0$ & $4 ; 5$ \\
C6 & $4 ; 5$ & $3 ; 4$ & $2 ; 2$ & $2 ; 3$ & $3 ; 4$ & $0 ; 0$ \\
\hline \multicolumn{7}{c}{ Expert 3 } \\
\hline C1 & C1 & C2 & C3 3 & C4 4 & C5 & C6 \\
\hline C2 & $5 ; 5$ & $5 ; 5$ & $4 ; 5$ & $3 ; 4$ & $5 ; 5$ & $4 ; 4$ \\
C3 & $3 ; 4$ & $2 ; 3$ & $3 ; 4$ & $4 ; 5$ & $5 ; 5$ & $4 ; 5$ \\
C4 & $3 ; 4$ & $3 ; 4$ & $3 ; 4$ & $5 ; 5$ & $4 ; 5$ & $5 ; 5$ \\
C5 & $2 ; 3$ & $1 ; 2$ & $2 ; 3$ & $1 ; 2$ & $3 ; 3$ & $4 ; 4$ \\
C6 & $3 ; 4$ & $4 ; 5$ & $3 ; 4$ & $3 ; 4$ & $3 ; 4$ & $4 ; 5$ \\
\hline
\end{tabular}

In accordance with the procedure for implementing the IR-DEMATEL model, the initial matrices of comparison in pairs of criteria are transformed into the interval rough matrices by means of Eqs. (1-11). Thus, we obtain three interval rough matrices of the criteria, Table 3 . 
Table 3 Interval rough matrices of comparisons in criteria pairs

\begin{tabular}{|c|c|c|c|c|}
\hline \multicolumn{5}{|c|}{ Expert 1} \\
\hline & $\mathrm{C} 1$ & $\mathrm{C} 2$ & $\ldots$ & C6 \\
\hline $\mathrm{C} 1$ & {$[(0,0),(0,0)]$} & {$[(3,3.67),(4,4.67)]$} & $\ldots$ & {$[(4,4.33),(4,4.33)]$} \\
\hline $\mathrm{C} 2$ & {$[(4,4.67),(5,5)]$} & {$[(0,0),(0,0)]$} & $\ldots$ & {$[(4.67,5),(5,5)]$} \\
\hline $\mathrm{C} 3$ & {$[(2,2.33),(3,3.33)]$} & {$[(1,2.33),(2,3.33)]$} & $\ldots$ & {$[(4,4.33),(4.67,5)]$} \\
\hline $\mathrm{C} 4$ & {$[(2,2.67),(2,3.33)]$} & {$[(3,3),(3,3.67)]$} & $\ldots$ & {$[(3,3.67),(4,4.33)]$} \\
\hline C5 & {$[(2,2),(3,3)]$} & {$[(1.67,2),(2,2.33)]$} & $\ldots$ & {$[(4.33,5),(5,5)]$} \\
\hline C6 & {$[(3,3.33),(4,4.33)]$} & {$[(2,2.67),(3,3.67)]$} & $\ldots$ & {$[(0,0),(0,0)]$} \\
\hline \multicolumn{5}{|c|}{ Expert 2} \\
\hline & $\mathrm{C} 1$ & $\mathrm{C} 2$ & $\ldots$ & $\mathrm{C6}$ \\
\hline $\mathrm{C} 1$ & {$[(0,0),(0,0)]$} & {$[(3.67,4),(4.67,5)]$} & $\ldots$ & {$[(4.33,5),(4.33,5)]$} \\
\hline $\mathrm{C} 2$ & {$[(4.67,5),(5,5)]$} & {$[(0,0),(0,0)]$} & $\ldots$ & {$[(4.67,5),(5,5)]$} \\
\hline C3 & {$[(2,2.33),(3,3.33)]$} & {$[(2.33,3),(3.33,4)]$} & $\ldots$ & {$[(4,4.33),(4,4.67)]$} \\
\hline $\mathrm{C} 4$ & {$[(2.67,3),(3.33,4)]$} & {$[(3,3),(3.67,4)]$} & $\ldots$ & {$[(3.67,4),(4.33,5)]$} \\
\hline C5 & {$[(2,2),(3,3)]$} & {$[(1,1.67),(2,2.33)]$} & $\ldots$ & {$[(4,4.33),(5,5)]$} \\
\hline C6 & {$[(3.33,4),(4.33,5)]$} & {$[(2.67,3),(3.67,4)]$} & $\ldots$ & {$[(0,0),(0,0)]$} \\
\hline \multicolumn{5}{|c|}{ Expert 3} \\
\hline & $\mathrm{C} 1$ & $\mathrm{C} 2$ & $\ldots$ & C6 \\
\hline $\mathrm{C} 1$ & {$[(0,0),(0,0)]$} & {$[(3.67,4),(4.67,5)]$} & $\ldots$ & {$[(4,4.33),(4,4.33)]$} \\
\hline $\mathrm{C} 2$ & {$[(4.67,5),(5,5)]$} & {$[(0,0),(0,0)]$} & $\ldots$ & {$[(4,4.67),(5,5)]$} \\
\hline $\mathrm{C} 3$ & {$[(2.33,3),(3.33,4)]$} & {$[(2.33,3),(3.33,4)]$} & $\ldots$ & {$[(4.33,5),(4.67,5)]$} \\
\hline $\mathrm{C} 4$ & {$[(2.67,3),(3.33,4)]$} & {$[(3,3),(3.67,4)]$} & $\ldots$ & {$[(3.67,4),(4,4.33)]$} \\
\hline C5 & {$[(2,2),(3,3)]$} & {$[(1.67,2),(2.33,3)]$} & $\ldots$ & {$[(4,4.33),(5,5)]$} \\
\hline $\mathrm{C} 6$ & {$[(3,3.33),(4,4.33)]$} & {$[(2.67,3),(3.67,4)]$} & $\ldots$ & {$[(0,0),(0,0)]$} \\
\hline
\end{tabular}

In the second step of the IR-DEMATEL model, using NWGBM, Eq. (14), the aggregation (averaging) of the interval rough matrices of the experts' responses is carried out. Thus, we obtain a centralized interval rough matrix of the average responses of the criteria experts, Table 4.

Table 4 Averaged interval rough matrix of criteria

\begin{tabular}{ccccc}
\hline & $\mathrm{C} 1$ & $\mathrm{C} 2$ & $\ldots$ & $\mathrm{C} 6$ \\
\hline $\mathrm{C} 1$ & {$[(0.0,0.0),(0.0,0.0)]$} & {$[(3.4,3.9),(4.4,4.9)]$} & $\ldots$ & {$[(4.1,4.5),(4.1,4.5)]$} \\
$\mathrm{C} 2$ & {$[(4.4,4.9),(5.0,5.0)]$} & {$[(0.0,0.0),(0.0,0.0)]$} & $\ldots$ & {$[(4.4,4.9),(5.0,5.0)]$} \\
C3 & {$[(2.1,2.6),(3.1,3.6)]$} & {$[(1.9,2.8),(2.9,3.8)]$} & $\ldots$ & {$[(4.1,4.6),(4.5,4.9)]$} \\
C4 & {$[(2.4,2.9),(2.9,3.8)]$} & {$[(3.0,3.0),(3.4,3.9)]$} & $\ldots$ & {$[(3.4,3.9),(4.1,4.5)]$} \\
C5 & {$[(2.0,2.0),(3.0,3.0)]$} & {$[(1.4,1.9),(2.1,2.6)]$} & $\ldots$ & {$[(4.1,4.6),(5.0,5.0)]$} \\
C6 & {$[(3.1,3.5),(4.1,4.5)]$} & {$[(2.4,2.9),(3.4,3.9)]$} & $\ldots$ & {$[(0.0,0.0),(0.0,0.0)]$} \\
\hline
\end{tabular}


Averaging of the elements of interval rough matrix of comparison in pairs of criteria at the $\mathrm{C} 3-\mathrm{C} 1$ position is performed by applying Eq. (14):

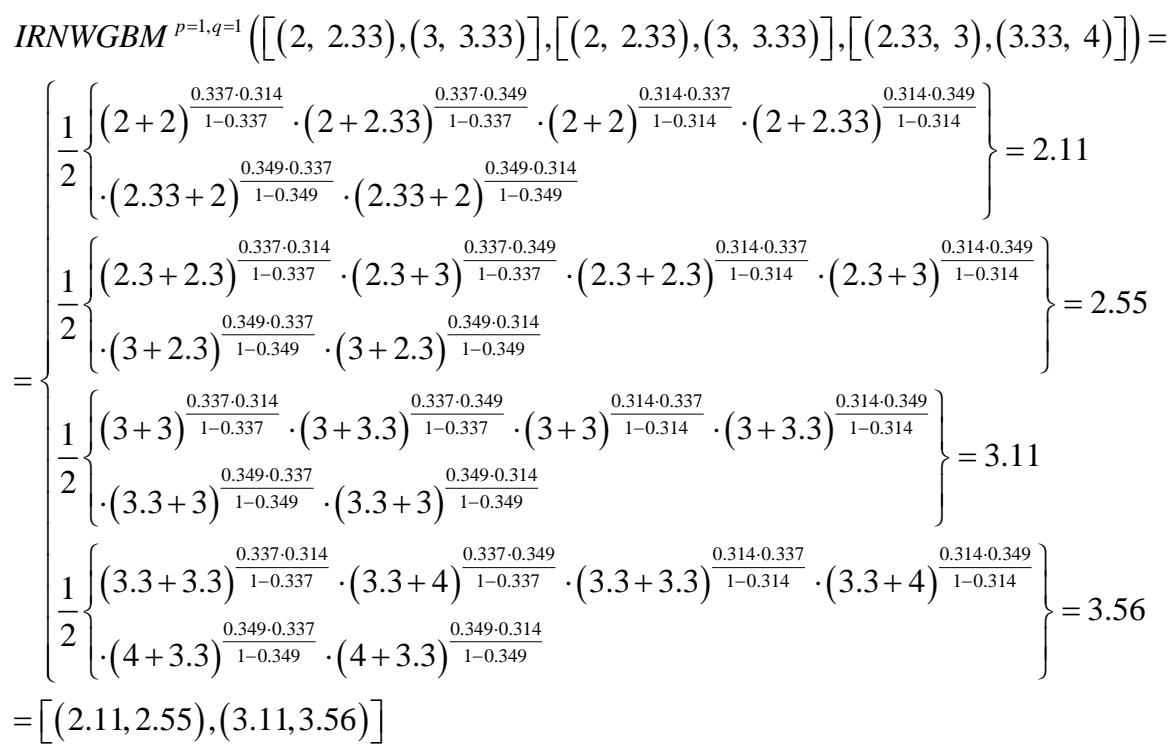

After determining the averaged matrix of criteria (Table 4), using Eqs. (18-20), the third step of the IR-DEMATEL model is carried out, which assumes the determination of the initial direct-relation matrix. In the next step, using Eqs. (21-23), the initial directrelation matrix is transformed into total relation matrix of the criteria. On the basis of total relation matrix, direct and indirect effects are determined (Table 5), which criterion $i$ provided to other criteria and received from other criteria, see Eqs. (24) and (25).

Table 5 Direct and indirect effects of the criteria

\begin{tabular}{ccccc}
\hline Criteria & IRN(Ri) & IRN(Ci) & IRN(wj) & Rank \\
\hline C1 & {$[(1.7,2.6),(2.9,5.0)]$} & {$[(1.3,1.9),(2.4,4.2)]$} & {$[(0.056,0.153),(0.205,0.548)]$} & 2 \\
C2 & {$[(1.8,2.8),(2.9,5.4)]$} & {$[(1.0,1.8),(2.0,4.3)]$} & {$[(0.054,0.158),(0.193,0.577)]$} & 1 \\
C3 & {$[(1.3,2.0),(2.3,4.4)]$} & {$[(1.3,2.0),(2.5,4.4)]$} & {$[(0.047,0.135),(0.182,0.522)]$} & 5 \\
C4 & {$[(1.4,2.0),(2.4,4.5)]$} & {$[(1.4,2.1),(2.4,4.4)]$} & {$[(0.051,0.138),(0.186,0.521)]$} & 6 \\
C5 & {$[(1.0,1.5),(2.1,3.6)]$} & {$[(1.6,2.4),(2.6,4.8)]$} & {$[(0.048,0.133),(0.183,0.500)]$} & 4 \\
C6 & {$[(1.2,1.8),(2.3,4.2)]$} & {$[(1.8,2.6),(2.9,5.0)]$} & {$[(0.055,0.151),(0.203,0.545)]$} & 3 \\
\hline
\end{tabular}

In the last step, using Eqs. (26-29), we obtain final interval rough weight coefficients of the criteria, Table 5.

After determining the weight coefficients of the criteria, the evaluation of the alternatives using the IR-COPRAS method is carried out. As with the IR-DEMATEL model, three experts evaluated six ways for the construction of a temporary military route. Experts evaluated the alternatives by assigning a certain value from the scale 1-9: 1 - very low influence; 2 - medium low influence; 3 - low influence; ...; 8 - high influence; 9 - very high influence. The results of the expert evaluation of the alternatives are shown in Table 6. 
Table 6 Expert evaluation of the alternative

\begin{tabular}{|c|c|c|c|c|c|c|}
\hline \multicolumn{7}{|c|}{ Expert 1} \\
\hline Alt./Crit. & $\mathrm{C} 1$ & $\mathrm{C} 2$ & $\mathrm{C} 3$ & $\mathrm{C} 4$ & $\mathrm{C} 5$ & C6 \\
\hline A1 & $(7 ; 8)$ & $(7 ; 8)$ & $(3 ; 4)$ & $(1 ; 2)$ & $(5 ; 6)$ & $(3 ; 4)$ \\
\hline A2 & $(9 ; 9)$ & $(7 ; 8)$ & $(5 ; 6)$ & $(9 ; 9)$ & $(7 ; 8)$ & $(9 ; 9)$ \\
\hline A3 & $(7 ; 8)$ & $(3 ; 4)$ & $(5 ; 6)$ & $(5 ; 6)$ & $(7 ; 8)$ & $(8 ; 9)$ \\
\hline A4 & $(9 ; 9)$ & $(7 ; 8)$ & $(7 ; 7)$ & $(9 ; 9)$ & $(9 ; 9)$ & $(8 ; 9)$ \\
\hline A5 & $(7 ; 8)$ & $(5 ; 6)$ & $(5 ; 5)$ & $(7 ; 8)$ & $(5 ; 6)$ & $(5 ; 6)$ \\
\hline A6 & $(7 ; 8)$ & $(7 ; 8)$ & $(7 ; 8)$ & $(5 ; 6)$ & $(7 ; 8)$ & $(7 ; 8)$ \\
\hline \multicolumn{7}{|c|}{ Expert 2} \\
\hline Alt./Crit. & $\mathrm{C} 1$ & $\mathrm{C} 2$ & $\mathrm{C} 3$ & $\mathrm{C} 4$ & C5 & C6 \\
\hline A1 & $(3 ; 4)$ & $(5 ; 6)$ & $(3 ; 4)$ & $(5 ; 6)$ & $(3 ; 4)$ & $(5 ; 5)$ \\
\hline A2 & $(9 ; 9)$ & $(8 ; 9)$ & $(5 ; 5)$ & $(7 ; 8)$ & $(7 ; 8)$ & $(9 ; 9)$ \\
\hline A3 & $(8 ; 9)$ & $(7 ; 8)$ & $(5 ; 6)$ & $(5 ; 6)$ & $(5 ; 6)$ & $(8 ; 9)$ \\
\hline A4 & $(9 ; 9)$ & $(9 ; 9)$ & $(7 ; 8)$ & $(9 ; 9)$ & $(8 ; 9)$ & $(8 ; 9)$ \\
\hline A5 & $(7 ; 8)$ & $(8 ; 9)$ & $(5 ; 6)$ & $(7 ; 8)$ & $(7 ; 8)$ & $(7 ; 8)$ \\
\hline A6 & $(6 ; 7)$ & $(7 ; 8)$ & $(7 ; 8)$ & $(5 ; 6)$ & $(7 ; 8)$ & $(5 ; 6)$ \\
\hline \multicolumn{7}{|c|}{ Expert 3} \\
\hline Alt./Crit. & $\mathrm{C} 1$ & $\mathrm{C} 2$ & $\mathrm{C} 3$ & $\mathrm{C} 4$ & $\mathrm{C} 5$ & C6 \\
\hline A1 & $(5 ; 6)$ & $(9 ; 9)$ & $(7 ; 8)$ & $(7 ; 8)$ & $(1 ; 2)$ & $(3 ; 3)$ \\
\hline A2 & $(9 ; 9)$ & $(9 ; 9)$ & $(9 ; 9)$ & $(8 ; 9)$ & $(9 ; 9)$ & $(9 ; 9)$ \\
\hline A3 & $(7 ; 8)$ & $(3 ; 4)$ & $(5 ; 6)$ & $(7 ; 8)$ & $(8 ; 9)$ & $(8 ; 9)$ \\
\hline A4 & $(9 ; 9)$ & $(8 ; 9)$ & $(8 ; 9)$ & $(9 ; 9)$ & $(8 ; 9)$ & $(8 ; 9)$ \\
\hline A5 & $(7 ; 8)$ & $(7 ; 8)$ & $(5 ; 6)$ & $(7 ; 8)$ & $(8 ; 9)$ & $(5 ; 6)$ \\
\hline A6 & $(5 ; 5)$ & $(3 ; 4)$ & $(5 ; 5)$ & $(7 ; 8)$ & $(8 ; 9)$ & $(5 ; 5)$ \\
\hline
\end{tabular}

Using Eqs. (1-11), the elements from Table 6 are transformed into interval rough numbers, which using Eq. (14) are aggregated into the initial decision-making matrix, Table 7.

Table 7 Initial decision-making matrix

\begin{tabular}{ccccc}
\hline Alt. & $\mathrm{C} 1$ & $\mathrm{C} 2$ & $\ldots$ & $\mathrm{C} 6$ \\
\hline A1 & {$[(3.99,6),(5,7)]$} & {$[(6.01,8.01),(6.9,8.4)]$} & $\ldots$ & {$[(3.21,4.08),(3.48,4.48)]$} \\
A2 & {$[(9,9),(9,9)]$} & {$[(7.5,8.5),(8.44,8.89)]$} & $\ldots$ & {$[(9,9),(9,9)]$} \\
A3 & {$[(7.11,7.54),(8.11,8.54)]$} & {$[(3.41,5.15),(4.42,6.15)]$} & $\ldots$ & {$[(8,8),(9,9)]$} \\
A4 & {$[(9,9),(9,9)]$} & {$[(7.49,8.49),(8.44,8.89)]$} & $\ldots$ & {$[(8,8),(9,9)]$} \\
A5 & {$[(7,7),(8,8)]$} & {$[(5.87,7.38),(6.87,8.38)]$} & $\ldots$ & {$[(5.21,6.09),(6.21,7.09)]$} \\
A6 & {$[(5.49,6.49),(5.87,7.38)]$} & {$[(4.72,6.54),(5.72,7.54)]$} & $\ldots$ & {$[(5.22,6.11),(5.6,7.1)]$} \\
\hline
\end{tabular}

Averaging of the elements of the evaluation matrices of alternatives at the A1-C2 position is carried out using Eq. (14): 


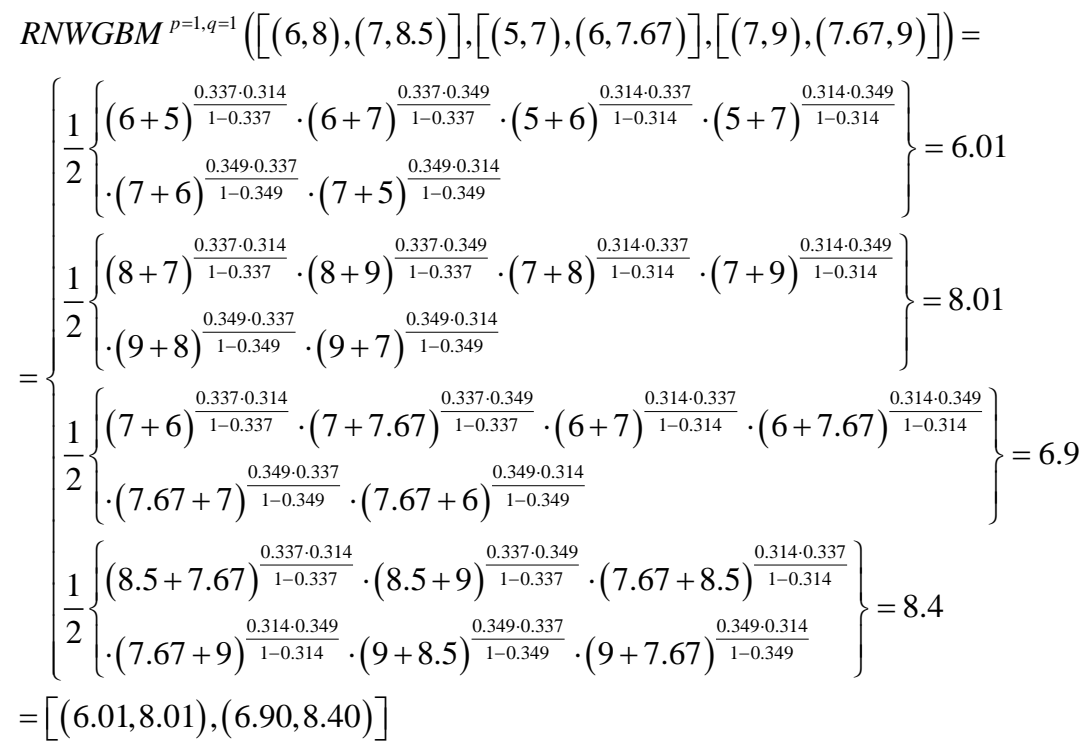

After normalizing the initial matrix using Eq. (32) and summing the elements of the normalized matrix using Eqs. (34-38), we obtain final rank of the alternative shown in Table 9.

Table 9 Values of criteria functions of alternatives and their ranking

\begin{tabular}{cccc}
\hline Alt. & $\operatorname{IRN}\left(Q_{i}\right)$ & $\operatorname{IRN}\left(P_{i}\right)$ & Rank \\
\hline A1 & {$[(0.06,0.17),(0.24,0.79)]$} & {$[(100.0,100.0),(100.0,100.0)]$} & 1 \\
A2 & {$[(0.03,0.13),(0.17,0.63)]$} & {$[(60.98,75.12),(67.99,80.04)]$} & 5 \\
A3 & {$[(0.04,0.15),(0.18,0.68)]$} & {$[(70.18,86.84),(72.43,86.29)]$} & 4 \\
A4 & {$[(0.03,0.13),(0.16,0.62)]$} & {$[(62.31,76.44),(65.62,78.41)]$} & 6 \\
A5 & {$[(0.04,0.15),(0.19,0.70)]$} & {$[(75.09,88.55),(78.12,87.79)]$} & 2 \\
A6 & {$[(0.04,0.15),(0.19,0.67)]$} & {$[(73.14,85.35),(78.57,85.00)]$} & 3 \\
\hline
\end{tabular}

In the following section, the analysis of the influence of parameters $p$ and $q$ from the IRNWBM operator to final ranges from the Table 9 was performed. The analysis assumes taking different values of parameters $p$ and $q$ and their impact on final values of the IRN weight coefficient of criteria, as well as the influence on the averaging of the value of the initial decision-making matrix or ranks from the Table 9. The considered values of parameters $p$ and $q$ and their influence on changing the alternatives rank are shown in Table 10. 
Table 10 Ranking order by different parameters $p$ and $q$

\begin{tabular}{|c|c|c|c|}
\hline $\begin{array}{l}\text { Parameters } \\
p \text { and } q\end{array}$ & Ranking order & $\begin{array}{c}\text { Parameters } \\
p \text { and } q\end{array}$ & Ranking order \\
\hline $\begin{array}{l}p=1 \\
q=1\end{array}$ & $A 1>A 5>A 6>A 3>A 2>A 4$ & $\begin{array}{l}p=5 \\
q=0\end{array}$ & $A 1>A 5>A 6>A 3>A 2>A 4$ \\
\hline $\begin{array}{l}p=0 \\
q=1\end{array}$ & $A 1>A 5>A 6>A 3>A 2>A 4$ & $\begin{array}{l}p=10 \\
q=10\end{array}$ & $A 1>A 5>A 6>A 3>A 2>A 4$ \\
\hline $\begin{array}{l}p=1 \\
q=0\end{array}$ & $A 1>A 5>A 6>A 3>A 2>A 4$ & $\begin{array}{l}p=0 \\
q=10\end{array}$ & $A 1>A 5>A 6>A 3>A 2>A 4$ \\
\hline $\begin{array}{l}p=2 \\
q=2\end{array}$ & $A 1>A 5>A 6>A 3>A 2>A 4$ & $\begin{array}{c}p=10 \\
q=0\end{array}$ & $A 1>A 5>A 6>A 3>A 2>A 4$ \\
\hline $\begin{array}{l}p=0 \\
q=2\end{array}$ & $A 1>A 5>A 6>A 3>A 2>A 4$ & $\begin{array}{l}p=50 \\
q=10\end{array}$ & $A 1>A 5>A 6>A 3>A 2>A 4$ \\
\hline $\begin{array}{l}p=2 \\
q=0\end{array}$ & $A 1>A 5>A 6>A 3>A 2>A 4$ & $\begin{array}{l}p=10 \\
q=50\end{array}$ & $A 1>A 5>A 6>A 3>A 2>A 4$ \\
\hline $\begin{array}{l}p=5 \\
q=5\end{array}$ & $A 1>A 5>A 6>A 3>A 2>A 4$ & $\begin{array}{l}p=50 \\
q=50\end{array}$ & $A 1>A 5>A 6>A 3>A 2>A 4$ \\
\hline $\begin{array}{l}p=0 \\
q=5\end{array}$ & $A 1>A 5>A 6>A 3>A 2>A 4$ & $\begin{array}{l}p=100 \\
q=100\end{array}$ & $A 1>A 5>A 6>A 3>A 2>A 4$ \\
\hline
\end{tabular}

Changes in the values of parameters $p$ and $q$ lead to certain changes of the values of the criteria functions of alternatives. However, the values of the criteria functions are such that they do not lead to changes in final ranges of alternatives, as shown in Table 10. Table 10 shows the influence of randomly selected values of parameters $p$ and $q$ on final ranges of alternatives in the IR-DEMATEL-COPRAS model. On the basis of the obtained results we can conclude that in the considered multi-criterion problem, changes of parameters $\mathrm{p}$ and $\mathrm{q}$ have no influence on the final rank of alternatives.

\section{CONCLUSION}

The recognition of imprecision and uncertainty in the multi-criteria decision-making is a very important aspect of an objective and impartial decision-making. There are often difficulties in presenting information about decision attributes by accurate (precise) numerical values. These difficulties are the result of doubts in the decision-making process just as they are due to the complexity and uncertainty of many real indicators. This paper presents a new approach to the exploitation of imprecision and uncertainty in group decision-making, which is based on interval rough numbers.

The application of interval rough numbers in the multi-criteria decision-making is presented through a hybrid model consisting of the IR-DEMATEL model and the IR-COPRAS method. In addition to the modification of the DEMATEL and the COPRAS models, the IRNWGBM operator for interval rough numbers is developed in this paper. The application of the IRDEMATEL-COPRAS model and the IRNNWGBM operator is presented through a case study in which the evaluation of alternatives for the construction of a temporary military route is performed. This study shows that the IRNNWGBM operator can be effectively applied in 
group decision-making models, respecting imprecision and uncertainty. Since this is a new IRN aggregator, which has not been applied as yet in the MCDM, the direction of future research should focus on the application of the IRNNWGBM in other models based on the IRN approach.

\section{REFERENCES}

1. Triantaphyllou, E., Mann, S.H., 1995, Using the analytic hierarchy process for decision making in engineering applications: some challenges, International Journal of Industrial Engineering: Applications and Practice, 2(1), pp. 35-44.

2. Chen, N., Xu, Z., Xia, M., 2015, The ELECTRE I Multi-Criteria Decision-Making Method Based on Hesitant Fuzzy Sets, International Journal of Information Technology \& Decision Making, 14(3), pp. 621-657.

3. Saaty, T. L., 1980, The Analytic Hierarchy Process, McGraw-Hill, NewYork.

4. Božanić, D., Pamučar, D., Bojanić, D., 2015, Modification of the Analytic Hierarchy Proces (AHP) Method using fuzzy logic: fuzzy AHP approach as a support to the decision making process concerning engagement of the Group for Additional Hindering, Serbian Journal of Management, 10(2), pp. 151-171.

5. Yoon, K., 1980, System Selection by Multiple Attribute Decision Making, PhD Thesis, Kansas State University, Manhattan, Kansas.

6. Opricovic, S., Tzeng, G.-H., 2004, The Compromise solution by MCDM methods: A comparative analysis of VIKOR and TOPSIS, European Journal of Operational Research, 156(2), pp. 445-455.

7. Tzeng, G.H., Chiang, C.H., Li, C.W., 2007, Evaluating intertwined effects in e-learning programs: a novel hybrid MCDM model based on factor analysis and DEMATEL, Expert Systems with Applications, 32(4), pp. 1028-1044.

8. Bernard, R., 1968, Classement et choix en présence de points de vue multiples (la méthode ELECTRE), La Revue d'Informatique et de Recherche Opérationelle (RIRO), 8, pp. 57-75.

9. Kaklauskas, A., Zavadskas, E.K., Raslanas, S., Ginevicius, R., Komka, A., Malinauskas, P., 2006, Selection of Low-e tribute in retrofit of public buildings by applying multiple criteria method COPRAS: A Lithuanian case, Energy and buildings, 38, pp. 454-462.

10. Pamučar, D., Ćirović G., 2015, The selection of transport and handling resources in logistics centers using Multi-Attributive Border Approximation area Comparison, Expert Systems with Applications, 42(6), pp. 3016-3028.

11. Bojanic, D., Kovač, M., Bojanic, M., Ristic, V., 2018, Multi-criteria decision-making in A defensive operation of THE Guided anti-tank missile battery: an example of the hybrid model fuzzy AHP $M A B A C$, Decision Making: Applications in Management and Engineering, 1(1), pp. 51-66.

12. Ghorabaee, M.K, Zavadskas, E.K., Olfat, L., Turskis, Z., 2015, Multi-Criteria Inventory Classification Using a New Method of Evaluation Based on Distance from Average Solution (EDAS), Informatica, 26(3), pp. 435-51.

13. Stević, Ž., Pamučar, D, Vasiljević, M., Stojić, G., Korica, S., 2017, Novel integrated multi-criteria model for supplier selection: Case study construction company, Symmetry, 9(11), 279, pp. 1-34.

14. Keshavarz G. M., Zavadskas, E. K., Turskis, Z., Antucheviciene, J., 2016, A new combinative distancebased assessment (CODAS) method for multi-criteria decision-making, Economic Computation \& Economic Cybernetics Studies \& Research, 50(3), pp. 25-44.

15. Badi, I.A., Abdulshahed, A.M., Shetwan, A.G., 2018, A case study of supplier selection for a steelmaking company in Libya by using the Combinative Distance-based ASsessment (CODAS) model, Decision Making: Applications in Management and Engineering, 1(1), pp. 1-12.

16. Pamučar, D., Vasin, Lj., Lukovac, L., 2014, Selection of railway level crossings for investing in security equipment using hybrid DEMATEL-MARICA model, XVI International Scientific-expert Conference on Railway, Railcon 2014, pp. 89-92, Niš.

17. Chatterjee, K., Pamučar, D., Zavadskas, E.K., 2018, Evaluating the performance of suppliers based on using the R'AMATEL-MAIRCA method for green supply chain implementation in electronics industry, Journal of Cleaner Production, 184, pp. 101-129.

18. Roy, J., Pamučar, D., Adhikary, K., Kar, S., 2018, A rough strength relational DEMATEL model for analysing the key success factors of hospital service quality, Decision Making: Applications in Management and Engineering, 1(1), pp. 121-142. 
19. Dombi, J., 1982, A general class of fuzzy operators, the demorgan class of fuzzy operators and fuzziness measures induced by fuzzy operators, Fuzzy Sets Syst, 8, pp. 149-163.

20. Bonferroni, C., 1950, Sulle medie multiple di potenze, Bollettino dell'Unione Matematica Italiana, 5, pp. 267-270.(Only in Italian).

21. Wang, W. Z., Liu, X.W., 2011, Intuitionistic fuzzy geometric aggregation operators based on Einstein operations, International Journal of Intelligent Systems, 26(11), pp. 1049-1075.

22. Xu, Z., Yager, R.R., 2006, Some geometric aggregation operators based on intuitionistic fuzzy sets, International Journal of General Systems, 35(4), pp. 417-433.

23. Herrera, F., Herrera-Viedma, E., Verdegay, L., 1996, A model of consensus in group decision making under linguistic assessments, Fuzzy Sets and Systems, 78(1), pp. 73-87.

24. Liu, P.D., Teng, F., 2016, An extended TODIM method for multiple attribute group decision-making based on 2-dimension uncertain linguistic variable, Complexity, 21, pp. 20-30.

25. Yang, W., Pang, Y., Shi, J., Yue, H., 2017, Linguistic hesitant intuitionistic fuzzy linear assignment method based on choquet integral, Journal of Intelligent \& Fuzzy Systems, 32(1), pp. 767-780.

26. Zhao, H., Xu, Z., Ni, M., Liu, S., 2010, Generalized aggregation operators for intuitionistic fuzzy sets, International Journal of Intelligent Systems, 25 (1), pp. 1-30.

27. Li, Y.H., Liu, P.D., Chen, Y.B., 2016, Some single valued neutrosophic number Heronian mean operators and their application in multiple attribute group decision making, Informatica, 27(1), pp. 85-110.

28. Ye, J., 2014, Multiple attribute group decision-making method with completely unknown weights based on similarity measures under single valued neutrosophic environment, Journal of Intelligent \& Fuzzy Systems, 27(6), pp. 2927-2935.

29. Ye, J., 2015, An extended TOPSIS method for multiple attribute group decision making based on single valued neutrosophic linguistic numbers, Journal of Intelligent \& Fuzzy Systems, 28 (1), pp. 247-255.

30. Fang, Z., Ye, J., 2017, Multiple Attribute Group Decision-Making Method Based on Linguistic Neutrosophic Numbers, Symmetry, 9(7), 111, pp. 1-12.

31. Liang, W., Zhao, G., Wu, H., 2017, Evaluating Investment Risks of Metallic Mines Using an Extended TOPSIS Method with Linguistic Neutrosophic Numbers, Symmetry, 9(8), 149, 1-18.

32. Ranjan, R., Chatterjee, P., Chakraborty, S., 2016, Performance evaluation of Indian railway zones using DEMATEL and VIKOR methods, Benchmarking: An International Journal, 23(1), pp.78 - 95.

33. Ranjan, R., Chatterjee, P., Chakraborty, S., 2015, Evaluating performance of engineering departments in an Indian University using DEMATEL and compromise ranking methods, OPSEARCH, 52(2), pp. 307-328.

34. Pamucar, D., Mihajlovic, M., Obradovic, R., Atanaskovic, P., 2017, Novel approach to group multicriteria decision making based on interval rough numbers: Hybrid DEMATEL-ANP-MAIRCA model, Expert Systems with Applications, 88, pp. 58-80.

35. Stević, Ž., Pamučar D, Zavadskas, E.K., Ćirović, G., Prentkovskis, O., 2017, The selection of wagons for the internal transport of a logistics company: A novel approach based on rough BWM and rough SAW methods, Symmetry, 9(11), 264, pp. 1-25.

36. Vasiljevic, M., Fazlollahtabar, H., Stevic, Z., Veskovic, S., 2018, A rough multicriteria approach for evaluation of the supplier criteria in automotive industry, Decision Making: Applications in Management and Engineering, 1(1), pp. 82-96.

37. Gigović, Lj., Pamučar, D., Bajić, Z., Milićević, M., 2016, The combination of expert judgment and GISMAIRCA analysis for the selection of sites for ammunition depot, Sustainability, 8(4), 372, pp. 1-30.

38. Wang, J., Tang, P., 2011, A rough random multiple criteria decision making method based on Interval rough operator, Control and decision making, 26(7), pp. 1056-1059.

39. Španović, I., 1983, Vojni putevi, VIZ, Belgrade. (Only in Serbian). 